\title{
Penerapan Rantai Nilai Global Sebagai Strategi Peningkatan Ekspor Produk Kopi
}

\author{
Arief Darmawan $^{1}$, Lili Adi Wibowo ${ }^{2}$, Adhie Surachman ${ }^{3}$ \\ Fakultas Ilmu Komunikasi, Universitas Subang ${ }^{1,3}$ FPEB, Universitas Pendidikan Indonesia ${ }^{2}$ \\ ariefdarmawan@unsub.ac.id \\ liliadiwibowo@upi.edu
}

\begin{abstract}
Abstrak
Petani kopi sebagai UMKM Hijau dapat menerapkan rantai nilai global (GVC) berbasis SDGs agar dapat membuka pangsa pasar ekspor yang lebih luas. Periode 2009-2018, terjadi penurunan pangsa ekspor kopi Indonesia secara signifikan, namun di sisi lain dampaknya pada pembentukan PDB tanaman perkebunan tampak tidak signifikan. Penelitian berusaha memetakan permasalahan tersebut dengan menganalisis hubungan antara variabel yang berperan pada pembentukan PDB (sebagai variabel dependen), yaitu volume produksi kopi, nilai ekspor kopi, harga ekspor kopi, dan kredit investasi UMKM selama periode 2009-2018. Penelitian menggunakan pendekatan kuantitatif berdasar untuk memperoleh model regresi linier berganda yang dapat memetakan masalah penelitian. Berdasarkan uji statistik, diketahui variabelvariabel penelitian berkontribusi positif dan signifikan pada peningkatan PDB Tanaman Perkebunan. Implikasi dari hasil adalah trend penurunan ekspor tersubtitusi booming permintaan kopi di dalam negeri yang didukung kredit investasi UMKM. Penerapan GVC dapat menjadi salah satu strategi untuk meningkatkan kembali pangsa ekspor kopi.
\end{abstract}

Kata Kunci: Rantai Nilai Global, Strategi, Peningkatan Ekspor, Produk Kopi.

\begin{abstract}
Coffee farmers as Green MSMEs can apply SDG-based global value chains (GVC) in order to open up a wider share of the export market. During the 2009-2018 period, there was a significant decline in the share of Indonesia's coffee exports, but on the other hand, the impact on the formation of the GDP of plantation crops seemed insignificant. The study attempts to map this problem by analyzing the relationship between the variables that play a role in the formation of GDP (as the dependent variable), namely the volume of coffee production, the export value of coffee, the export price of coffee, and the MSME investment credit during the 2009-2018 period. This research uses a quantitative based approach to obtain multiple linear regression models that can map research problems. Based on statistical tests, the research variables have a positive and significant contribution to the increase in the GDP of plantation crops. The implication of the results is the trend of declining exports substituted by the booming demand for coffee in the country supported by MSME investment credit. The application of GVC can be one strategy to increase the share of coffee exports again.
\end{abstract}

Keywords: Global Value Chain, Strategy, Increasing Export, Coffee Product.

\section{PENDAHULUAN}

Pemerintah memproyeksikan pada akhir 2020 kontribusi UMKM terhadap volume ekspor Indonesia dapat meningkat menjadi 18 persen dari tahun sebelumnya tahun 2019 sebesar 14 persen. Termasuk target kontribusi UMKM pada PDB nasional meningkat sampai dengan 61 persen, sedangkan rasio kewirausahaan naik menjadi 3,55 persen. Target pada
2024 mendatang, ditargetkan ekspor UMKM sudah harus bisa lebih dari 30,20 persen, yang kontribusi terhadap PDB 65 persen, sedangkan rasio kewirausahaan diharapkan bisa mencapai 4 persen (Kusdiyanti, Febrianto, \& Wijaya, 2020). Saat ini ada sekitar 60 juta pengusaha UMKM, atau sekitar 99 persen dari total pengusaha nasional, namun belum berkontribusi siginifikan terhadap pertumbuhan ekonomi nasional (Irawan, 2019). Bandingkan dengan 
usaha besar yang hanya 1 persen namun memiliki kontribusi terhadap PDB sebesar 40 persen dan ekspor 80 persen. Untuk tenaga kerja, UMKM berhasil menyerap 121 juta tenaga kerja. Angka tersebut sekitar $96 \%$ dari serapan tenaga kerja Indonesia di tahun 2018 yang sebesar Rp170 juta (Bank Indonesia, 2019).

Studi yang dilakukan lembaga donor seperti World Bank dan ADB menunjukkan bahwa secara umum kontribusi UMKM Indonesia terhadap sektor ekspor dengan menerapkan rantai nilai global (GVC) masih rendah. Partisipasi yang rendah ini disebabkan keterbatasan sumber daya seperti keuangan, manajemen dan teknologi, serta akses terhadap informasi pasar (Anam, 2019). UMKM yang bergerak pada sektor perkebunan, dapat berperan besar pada penciptaan PDB melalui komoditas ekspor dengan konsep GVC. Salah satu komoditas perkebunan yang telah ratusan tahun menjadi salah satu primadona ekspor Indonesia adalah produk kopi. Total produksi kopi Indonesia pada 2015 sebesar 636,4 ribu ton meningkat menjadi 722,4 ribu ton pada tahun 2018 (BPS RI, 2020). Sebagian besar produksi kopi tersebut adalah hasil UMKM Hijau (UMKM yang bergerak di sektor pertanian dan perkebunan). Perusahaan besar baik swasta dan BUMN hanya menghasilkan sekitar 4-5\% saja dari total produksi kopi di seluruh Indonesia, sehingga peran UMKM Hijau memiliki peran penting dalam keberlanjutan komoditas kopi menjadi primadona ekspor Indonesia.

Dalam 15 tahun terakhir, meskipun jumlah produksi kopi semakin meningkat, namun pangsa ekpor kopi Indonesia semakin menurun, dari $5,1 \%$ pada 2005 , menjadi 3,8\% pada tahun 2015 (Rosiana et.al, 2017). Penurunan tersebut seiring dengan pergeseran tujuan ekspor kopi Indonesia. Pada tahun 2005, Amerika Serikat, Jepang, dan Jerman menjadi tujuan utama ekspor kopi Indonesia, namun hari ini turun, menjadi sekitar sepertiga dari total ekspor kopi Indonesia (Jamil, 2019). Sebagian alasannya adalah penurunan daya saing akibat diterapkannya peraturan keamanan makanan yang lebih ketat di Amerika Serikat, UE dan Jepang, seiring dengan penerapan ekonomi hijau dan prinsip keberlanjutan SDGs. Sebagai contoh di Jerman, peraturan terkait SDGs ini berkontribusi pada penurunan impor sebesar 30 juta kilogram sejak tahun 2009. Trend tersebut telah menggeser tujuan ekspor kopi Indoensi untuk memenuhi permintaan yang lebih kuat dari pasar negara ASEAN, seperti Malaysia dan Thailand, serta ekonomi regional utama lainnya seperti Italia, Rusia dan Mesir (OECD/ERIA, 2018). Namun tren terbaru, menunjukkan ekspor ke Italia meningkat secara signifikan, karena pembuat kopi dan penjual kopi (Cafe) khas Italia menggunakan campuran Robusta Indonesia yang mengandung paling sedikit pestisida dibandingkan produk kopi negara lainnya (TPSA, 2017).

Kewirausahaan petani kopi sebagai UMKM yang berperan berkontribusi langsung pada laju pertumbuhan ekonomi, sejalan dengan teori yang dikembangkan oleh Kirzner, Hausmann dan Rodrik, bahwa wirausahawan adalah agen penting dalam menggerakkan proses penemuan yang diperlukan untuk menghasilkan pertumbuhan dan menyeimbangkan pasar (Patrick, 2017). Sebagai contoh, kekuatan wirausaha UMKM yang menjadi unggulan negaranya masing-masing, seperti UMKM garmen di Bangladesh, perangkai bunga di Kolombia, dan pemrograman teknologi informasi (TI) di India. Teori ini mendukung gagasan bahwa kewirausahaan menghasilkan pertumbuhan dengan menciptakan peluang ekonomi baru, merangsang persaingan dan mendorong peningkatan produktivitas dalam suatu ekonomi (Irawan, 2020). Fenomena jaringan produksi atau rantai nilai (GVC) berdasarkan pada teori fragmentasi, yang dikenal sebagai pembagian produksi lintas-batas pasar, daerah, dan negara. Teori fragmentasi berfokus pada berbagai lokasi proses produksi dan lokasi assembling sebagai intinya (Kano, Tsang, \& Yeung, 2020).

\section{METODE PENELITIAN}

Tujuan penelitian ini adalah membuat suatu model analisis yang dapat memetakan hubungan/keterkaitan antara Produk Domestik Bruto (PDB) tanaman perkebunan dengan faktor-faktor pembentuknya, yaitu volume produksi, nilai ekspor, harga ekspor produk di pasar dunia, dan kredit investasi. Model analisis menggunakan uji statistik regresi linier berganda, untuk memperoleh jawaban ilmiah parametrik mengenai trend penurunan distribusi sektor pertanian, khususnya tanaman perkebunan terhadap komposisi PDB nasional. Selama ini banyak peneliti cenderung lebih melihat produktivitas (Prasanna et al., 2019) dan (Ogundipe, Adu, Ogundipe, \& Asaleye, 2019); pengaruh nilai tukar (Kala, Masbar, \& Syahnur, 2018) dan (Şen, Kaya, Kaptan, \& Cömert, 2020); kesiapan SDM (Roostika, 2019) dan (Thanh, Nhat, Dang, Ho, \& Lebailly, 2018); dan yang paling banyak memilih tingkat inflasi (Blinov, 2017), (Lutfiana, 2017), (Larasati \& Sulasmiyati, 2018), (Aulia, Saleh, \& Roy, 2018), (Karlina, 2017), dan (Silaban \& Rejeki, 2020) dalam menilai kontribusi suatu sektor terhadap PDB. Faktorfaktor pada penelitian sebelumnya tersebut belum memetakan secara mendalam karakteristik PDB per 
sektor khususnya terkait UMKM dan karakteristiknya dalam berkontribusi terhadap PDB secara berkelanjutan.

Penelitian ini menggunakan pendekatan kuantitatif berdasarkan data deret waktu (time series). Metode peramalan kuantitatif menggunakan deret waktu banyak digunakan untuk obyek penelitian yang bersifat tetap dan tidak dinamis, umumnya terbagi menjadi dua jenis metode, yaitu causal dan time series (Green \& Armstrong, 2012). Analisis dengan menggunakan teknik deret waktu meliputi variabelvariabel yang mewakili faktor dan fenomena yang berhubungan, untuk menggambarkan pola atau kecenderungan umum, yang dibuktikan dengan analisis regresi (Benkachcha, Benhra, \& El Hassani, 2015). Teknik deret waktu merupakan metode kuantitatif yang murah banyak digunakan dalam penelitian untuk menganalisis data masa lampau yang telah diklasifikasikan berdasarkan sumber data terpercaya (valid) dan menggunakan teknik yang sesuai. Sehingga model deret waktu lebih disukai dan telah digunakan dalam banyak aplikasi seperti: Peramalan Ekonomi, Peramalan Penjualan, Analisis Anggaran, Analisis Pasar Saham, Proses dan Kontrol Kualitas dan Studi Inventaris Logistik, dan banyak lagi (Gosasang, Chandraprakaikul, \& Kiattisin, 2011). Model pemetaan yang dibangun berdasar variabel penelitian yang dipilih dapat dilihat pada bagan di bawah ini, meliputi faktor-faktor yang diperkirakan (hipotesa) memiliki hubungan dan pengaruh yang kuat terhadap pertumbuhan PDB Tanaman Perkebunan.

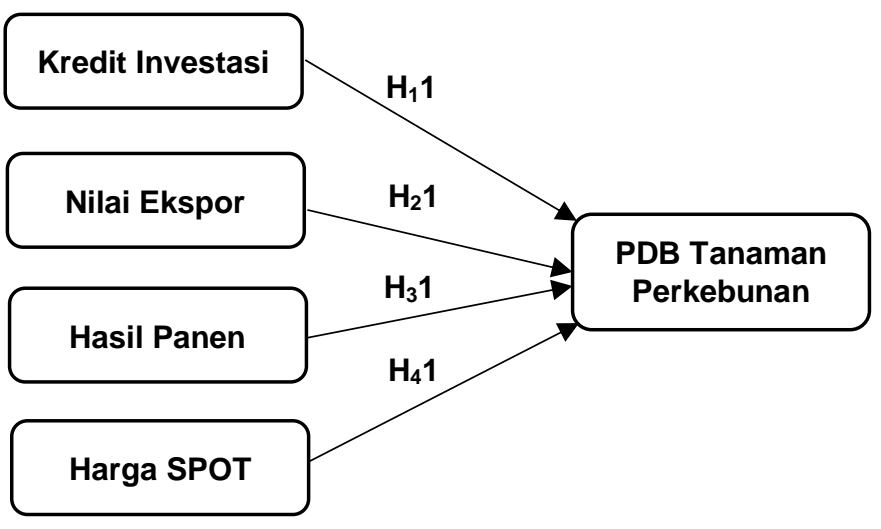

Gambar 1. Identifikasi Faktor-Faktor yang Berpengaruh pada PDB Tanaman Perkebunan

Faktor-faktor tersebut dioperasionalisasi menjadi variabel penelitian yaitu variabel bebas (independent), yang dapat menerangkan variabel terikat, yang meliputi kredit investasi UMKM, selama periode 2009-2018 dengan puluh triliun rupiah. Nilai ekspor kopi, selama periode 2009-2018 dengan satuan puluh ribu USD. Hasil panen kopi UMKM Hijau (petani kopi), selama periode 2009-2018 dengan satuan ribu metrik ton. Harga kopi dunia, selama periode 20092018 dengan satuan sen USD/kg. Sedangkan variabel terikatnya (dependent), yaitu pertumbuhan PDB tanaman perkebunan yang menjadi variabel terikat (dependent), selama periode 2009-2018 dengan puluh triliun rupiah.

Jenis data sekunder yang digunakan adalah data deret waktu berupa data statistik sepuluh tahun terakhir periode 2009-2018, yang meliputi data Produk Domestik Bruto (PDB) khusus sektor Perkebunan yang menjadi variabel terikat (dependent). Sedangkan faktor-faktor yang ditengarai berpengaruh pada PDB sektor perkebunan adalah Produksi Kopi berorientasi ekspor, Nilai Ekspor Kopi, Harga kopi dunia (dalam USD), dan pertumbuhan Kredit Investasi UMKM. Keempat faktor berpengaruh tersebut menjadi variabel bebas.

\section{HASIL DAN PEMBAHASAN}

Berdasarkan hasil regresi linier berganda menggunakan SPSS versi 22, diperoleh hasil analisis statistik sebagai berikut.

Koefisien determinan, Hasil regresi linier berganda diperoleh nilai adjusted $\mathrm{R}$ Square sebesar 0,996. Berarti variabel bebas dapat menjelaskan varians dari variabel terikatnya adalah sebesar $99,6 \%$, sedangkan $0,4 \%$ lagi dijelaskan oleh faktor lain.

Dengan demikian, model penelitian dapat digunakan untuk memprediksi hubungan antara pertumbuhan PDB sebagai variabel dependen dengan perkembangan variabel bebas (perkembangan kredit investasi, nilai ekspor kopi, volume produksi kopi, dan harga ekspor) yang digunakan dalam model.

Berhasilkan uji ANOVA, untuk tingkat kepercayaan 5\% diperoleh nilai $\mathrm{F}$ hitung sebesar 517,87 dengan Signifikansi 0,000 . Membandingkan dengan nilai $\mathrm{F}$ tabel di mana df $1=\mathrm{k}-1=3$ dan df2 $=\mathrm{n}-\mathrm{k}=10-4=6$, diperoleh nilai $\mathrm{F}$ tabel 4,76. Karena Fhitung > Ftabel dan signifikasi uji $\mathrm{F}<0,05$ maka Ho ditolak, artinya variabel-variabel bebas yang diuji secara simultan mempunyai pengaruh terhadap variabel terikat. 
12 Coopetition, Vol XII, Nomor 1, Maret 2021, 9 - 16

(E-ISSN : 2615-4978, P-ISSN : 2086-4620)

Tabel 1. Hasil Uji Statistik Regresi Linier

\begin{tabular}{lllllll} 
& & \multicolumn{5}{c}{ Std. } \\
Model & B & Error & Beta & Sig. \\
\hline 1 & (Constant) & $-20,544$ & 5,720 & & $-3,592$ &, 016 \\
\cline { 2 - 5 } & Kredit & $\mathbf{1 , 2 2 5}$ &, 032 & 1,055 & $\mathbf{3 7 , 7 4 8}$ & $\mathbf{, 0 0 0}$ \\
\hline Ekspor & $\mathbf{, 0 1 0}$ &, 012 &, 020 & $\mathbf{, 8 2 0}$ & $\mathbf{4 4 9}$ \\
\hline Panen & $\mathbf{4 5 5}$ &, 076 &, 152 & $\mathbf{6 , 0 1 0}$ & $\mathbf{, 0 0 2}$ \\
\hline Harga & $\mathbf{2 7 9}$ &, 048 &, 174 & $\mathbf{5 , 8 3 4}$ & $\mathbf{, 0 0 2}$ \\
\hline
\end{tabular}

(Sumber: Hasil Pengolahan Data 2020)

Dari tabel koefisien di atas, untuk tingkat kepercayaan $5 \%$ diperoleh nilai konstanta persamaan regeresi (B), t hitung dan signifikansi untuk masingmasing variabel bebas. Analisis uji t membandingkan $\mathrm{t}$ hitung masing-masing variabel bebas dengan $\mathrm{t}$ tabel. Nilai $\mathrm{t}$ tabel diperoleh dari tabel $\mathrm{t}$ dengan rumus : $\mathrm{t}$ tabel $=(\alpha / 2 ; n-k-1$ atau nilai residual df $)$, maka diperoleh $\mathrm{t}$ tabel $(0,25 ; 5)$ dengan nilai 2,571 . Sehingga dapat dianalisis hasil uji $\mathrm{t}$ masing-masing variabel bebas. Variabel bebas Harga $\left(\mathrm{H}_{1}\right)$, memperoleh nilai thitung 5,834> ttabel 2,571 dan nilai signifikansi uji t 0,002 < 0,05 maka Ho ditolak, artinya berdasar hasil uji. variabel Harga secara parsial memiliki pengaruh terhadap variabel PDB. Variabel bebas Panen $\left(\mathrm{H}_{2}\right)$, memperoleh nilai thitung 6,010 > ttabel 2,571 dan nilai signifikansi uji t 0,002 $<0,05$ maka Ho ditolak, artinya berdasar hasil uji, variabel Panen secara parsial memiliki pengaruh terhadap variabel PDB.Variabel bebas Ekspor $\left(\mathrm{H}_{3}\right)$, memperoleh nilai thitung $0,820<$ ttabel 2,571 dan nilai signifikansi uji t 0,449>0,05 maka Ho diterima, artinya berdasar hasil uji, variabel Ekspor secara parsial tidak memiliki pengaruh terhadap variabel PDB. Variabel bebas Kredit $\left(\mathrm{H}_{4}\right)$, memperoleh nilai thitung 37,748 > ttabel 2,571 dan nilai signifikansi uji t $0,000<0,05$ maka Ho ditolak, artinya berdasar hasil uji, variabel Kredit secara parsial memiliki pengaruh terhadap variabel PDB.

Berdasarkan hasil analisa statistik diperoleh konstanta persamaan regresi liner sebagai berikut :

$Y=-20,544+1,225 X_{1}+0,010 X_{2}+0,455 X_{3}+0,279 X_{4}-->(1)$

Berdasarkan persamaan di atas dan hasil signfikansi uji statistik, maka dapat diyakini bahwa peningkatan kredit investasi, produktivitas tanaman kopi, dan kenaikan harga kopi dunia (dalam USD) baik secara bersama-sama atau pun masing-masing (parsial), berkontribusi positif dan signifikan pada peningkatan PDB Tanaman Perkebunan. Meskipun memiliki hubungan positif, pada periode 2009-2018 kegiatan ekspor tidak berpengaruh atau memiliki kontribusi signfikan pada peningkatan PDB. Hal ini membuktikan bahwa penurunan pangsa pasar ekspor kopi menyebabkan berkurangnya kontribusi dan distribusi komoditas kopi terhadap PDB tanaman perkebunan secara signifikan. Di sisi lain, peningkatan kredit investasi UMKM tampak berpengaruh langsung dan signifikan pada laju peningkatan PDB tanaman perkebunan, padahal dalam periode 2009-2018 ekspor komoditas perkebunan (khususnya kopi) cenderung menurun. Hal ini mengindikasikan penggunaan dana bank untuk diversifikasi dan pengembangan pasar kopi dalam negeri yang berkontribusi pada PDB. Diversikasi tersebut dapat dirasakan dengan ekpansi bisnis para petani kopi untuk melakukan branding sendiri seperti kemunculan berbagai kopi premium (specialty) di berbagai daerah (indikasi geografis), seperti Kopi Arabika Gayo, Kopi Arabika Kintamani Bali, Kopi Arabika Flores Bajawa, Kopi Arabika Java Preanger, Kopi Robusta Lampung, Kopi Robusta Empat Lawang, dan banyak lainnya. Begitu pula upaya penetrasi ke pasar pengguna akhir melalui pembukaan Cafe di kota besar dan berbagai usaha frenchise kedai kopi (Djuwendah, Karyani, Sadeli, \& Kusno, 2018). Eforia kopi dalam negeri dalam 10 tahun terakhir, selain memunculkan nama-nama besar cafe baru (Coffee Shop) seperti J-Co, Coffee Bean, Excelso, Ngopi Doeloe, dan banyak lagi di tingkat nasional, juga mengundang pemain besar cafe kelas dunia seperti Starbuck, Maxx Coffee, Coffee Toffee, Gade Coffee \& Gold yang telah membuka sekitar 645 gerai di seluruh Indonesia dalam 10 tahun terakhir (Mcdonald, 2019).

Kurang berperannya nilai ekspor kopi dibandingkan kredit investasi pada 10 tahun terakhir terhadap PDB tanaman perkebunan, dapat lebih dijelaskan oleh gambar 2 di atas. Perkembangan permintaan Ready to Drink Coffee (RTD) atau kopi siap minum di Indonesia dalam 5 tahun terakhir tumbuh lebih dari $300 \%$, selain di Cafe, kopi siap minum saat ini bisa ditemukan di hampir seluruh toko retail seperti Alfamart, Indomart, Yomart, dan banyak lagi. Produk kopi yang dihasilkan UMKM Hijau tetap terserap dan semakin diminati pasar dalam negeri, sehingga tetap menyumbang kontribusi pada PDB. Kekosongan (Gap) pangsa kopi Indonesia di pasar dunia (separuh hasil panen terserap pasar dalam negeri), saat ini diisi oleh kopi Vietnam, meskipun memiliki lahan perkebunan kopi tidak seluas Indonesia namun Vietnam berusaha keras agar produknya dapat masuk ke pasar premium EU dan AS dengan menerapkan rantai nilai global (GVC) dan memenuhi persyaratan sertifikasi produk ramah lingkungan (Thu, 2018). 
Meskipun berdasarkan hasil uji statistik memperlihatkan penurunan nilai ekspor tidak mempengaruhi kontribusi PDB tanaman perkebunan (hanya memperlambat pertumbuhan), namun puncak penurunan ekspor kopi hingga 30\% pada tahun 2018 (dari 416 ton pada tahun 2017 menjadi 294 ton pada tahun 2018) harus menjadi perhatian semau pihak. Karena di sisi lain faktor-faktor ekonomi terkait seperti harga ekspor kopi, produksi kopi, dan kredit perbankan UMKM cenderung meningkat. Penurunan nilai dan pangsa ekspor Indonesia merupakan masalah sistemik yang melibatkan seluruh pihak. Karena keterpurukan ekspor kopi menyebabkan jatuhnya harga kopi di tingkat petani, yang berpotensi menambah bukan mengurangi tingkat kemiskinan. Sebagai ilustrasi, pada tahun 2018, terdapat 1.193.628 petani kopi/UMKM Hijau yang berperan sebagai produsen 95\% kopi nasional. Total luas lahan kopi di Indonesia pada tahun 2018 tercatat sebesar 1.193.628 Ha. Maka rata-rata penguasaan lahan per UMKM sekitar $1 \mathrm{Ha}$. Menggunakan data produktivitas lahan tahun 2017, produksi per hektar per pertani sebesar $744 \mathrm{~kg}$ (Rosiana et al., 2017). Bandingkan dengan petani kopi Vietnam pada periode yang sama, produktivitas lahan kopi bisa mencapai 2 ton per hektar, maka per petani bisa memperoleh pendapatan yang lebih besar, padahal Vietnam hanya memiliki lahan perkebunan kopi sekitar 500 ribu hektar atau sekitar $42 \%$ dari total lahan perkebunan kopi Indonesia.

Mulai tahun 2018, buyer kopi raksasa seperti Nestle dan Starbuck menargetkan 70\% bahan baku kopinya bersertifikat ramah linkungan/ berkelanjutan (Bray, 2019). Fenomena tersebut semakin mendorong urgensi penerapan GVC pada UMKM penghasil komoditas ekspor Indonesia khususnya kopi. Namun penerapan GVC tidak bisa terburu-buru, perlu strategi, perencanaan, pembiayaan, dan pelaksanaan yang melibatkan semua stakeholder secara sinergis. Perlu diciptakan lingkungan operasi dan model relasi kopi yang yang melibatkan organisasi petani, didukung kebijakan pemerintah untuk mengutamakan penerapan GVC (Rusdiana \& Maesya, 2018), misalnya dengan memberikan peran besar kepada BUMDES agar dapat menjadi agen GVC dan penyelenggaraan sertifikasi ramah lingkungan. Penerapan pasar bersama ASEAN merupakan contoh GVC pada UMKM Hijau yang telah dimanfaatkan secara maksimal oleh para petani buah di Thailand, produsen kopi Vietnam, dan pabrikan Sawit di Malaysia untuk menggenjot produksi dan ekspornya, tanpa perlu membuka lahan baru, melatih banyak pekerja, dan banyak investasi pabrik baru.

\section{SIMPULAN DAN SARAN}

\section{Simpulan}

Penelitian telah berhasil menjawab pertanyaan mengenai tidak berpengaruhnya nilai ekspor terhadap pertumbuhan PDB tanaman perkebunan selama periode 2009-2018. Ternyata kontribusi ekspor dari produk kopi tersubtitusi booming permintaan kopi di dalam negeri. Didukung kredit investasi UMKM perbankan, pergeseran volume produksi ke pasar dalam negeri tetap dapat berkontribusi signifikan terhadap PDB tanaman perkebunan.

Berdarah-darahnya ekspor kopi Indonesia perlu segera ditangani secara sistemik, bagi perbaikan ekonomi UMKM produsen kopi. Karena penurunan nilai ekspor bukan disebabkan oleh menurunnya permintaan pasar luar negeri atau terpuruknya harga ekspor, mengingat Kopi Indonesia dinilai paling ramah lingkungan (kadar perstisida paling kecil) sehingga tetap dicari. Vietnam yang sejak tahun 2019 ini berhasil menggeser Brazil dari puncak ekportir kopi terbesar dunia, padahal hanya memiliki lahan kopi kurang dari separuh lahan kopi Indonesia, hal ini bisa menjadi benchmark dalam memberdayakan UMKM Hijau.

Penerapan GVC yang berbasis prinsip SDGs selain sejalan dengan kebijakan ekonomi hijau yang diterapkan Pemerintah pada RPJMN 2020-2024, dapat memberdayakan para petani kopi untuk memanfaatkan secara maksimal peluang pasar yang saat ini sedang booming baik untuk pasar dalam negeri atau pun ekspor. Lembaga ekonomi lokal seperti BUMDES dan KUD, dapat berperan menjadi agen GVC yang memfasilitasi UMKM Hijau dalam penerapan standar produk dan sertifikasi ramah lingkungan sebagai prasyarat ekspor.

\section{Saran}

Para pemangku kepentingan terkait komoditas kopi di Indonesia perlu segera mengadopsi prinsip-prinsip SDGs, seperti yang dipersyaratkan oleh industri kopi global, seperti Nestle dan Starbuck, dan lainnya. Pengadopsian tersebut diharapkan dapat menciptakan kanal-kanal pemasaran baru berdasarkan GVC yang memungkinkan transaksi secara BtoB dengan UMKM. Sekaligus untuk mengantisipasi pergeseran perilaku konsumen di era revolusi industri 4.0 yang lebih peduli terhadap produk ramah lingkungan, memunculkan beragam platform e-commerce yang memungkin end-user atau perorangan untuk bertransaksi dengan para produsen komoditas/produk yang telah tersertifikasi ramah lingkungan. 
14 Coopetition, Vol XII, Nomor 1, Maret 2021, 9 - 16

(E-ISSN : 2615-4978, P-ISSN : 2086-4620)

\section{UCAPAN TERIMA KASIH}

Ucapan terimakasih kami sampaikan kepada dosendosen Prodi S3 manajemen Universitas Pendidikan Indonesia yang telah memberikan saran yang konstruktif dalam penyelesaian artikel ini.

\section{DAFTAR PUSTAKA}

Anam, K. (2019). Government Strategy In The Development Of Msme In Jepara District. Journal of Political and Government Studies, 8(3), 211-220.

Aulia, S., Saleh, M., \& Roy, J. (2018). Pengaruh inflasi dan suku bunga terhadap investasi dan pertumbuhan ekonomi. Jurnal Ilmu Ekonomi Mulawarman (JIEM), 2(3), 38-45. https://doi.org/10.29264/JIEM.V2I3.1381

Bank Indonesia. (2019). Kajian Ekonomi dan Keuangan Regional - Laporan nusantara November 2019. Jakarta.

Benkachcha, S., Benhra, J., \& El Hassani, H. (2015). Seasonal Time Series Forecasting Models based on Artificial Neural Network. International Journal of Computer Applications,116(20),914.

Blinov, S. (2017). Inflation and economic growth. Journal of Economics Library, 4(2), 227-237.

BPS RI. (2020). Ekspor Menurut Kelompok Komiditi dan Negara - Maret 2020. In Buletin Statistik Perdagangan Luar Negeri -. Jakarta.

Bray, J. G. P. (2019). Institutional environments and the livelihood impacts of voluntary sustainability standards: A Village-based analysis from southern Sumatra's coffee sector. Singapore Journal of Tropical Geography, Vol. 40 , pp.

291-311. https://doi.org/10.1111/sjtg.12275

Djuwendah, E., Karyani, T., Sadeli, A. H., \& Kusno, K. (2018). Agroindustrialisasi Kopi Arabika Java Preanger di Desa Margamulya Kecamatan Pangalengan Kabupaten Bandung. AGRICORE, $3(1)$.

Gosasang, V., Chandraprakaikul, W., \& Kiattisin, S. (2011). A Comparison of Traditional and Neural Networks Forecasting Techniques for Container Throughput at Bangkok Port. Asian Journal of Shipping and Logistics, 27(3), 463482.https://doi.org/10.1016/S2092-

5212(11)80022-2
Green, K. C., \& Armstrong, J. S. (2012). Demand Forecasting: Evidence-Based Methods. SSRN Electronic Journal, 165(October), 1-27. https://doi.org/10.2139/ssrn.3063308

Irawan, D. (2019). Pengembangan Kemitraan Koperasi, Usaha Mikro Dan Kecil (KUMK) Dengan Usaha Menengah/Besar Untuk Komoditi Unggulan Lokal. Coopetition : Jurnal Ilmiah Manajemen, 9(1), 53-66. https://doi.org/10.32670/coopetition.v9i1.52

Irawan, D. (2020). Peningkatan Daya Saing Usaha Micro Kecil dan Menengah Melalui Jaringan Usaha. Coopetition: Jurnal Ilmiah Manajemen, $X(2), 103-116$.

Jamil, A. S. (2019). Daya Saing Perdagangan Kopi Indonesia di Pasar Global. Agriekonomika, 8(1), 26.

https://doi.org/10.21107/agriekonomika.v8i1.49 24

Kala, G., Masbar, R., \& Syahnur, S. (2018). the Effect of Exchange Rate, Inflation, Capital and Labor Force on Economic Growth in Indonesia. Jurnal Ekonomi Dan Kebijakan Publik Indonesia, 5(1), 35-50.

Kano, L., Tsang, E. W. K., \& Yeung, H. W. (2020). Global Value Chains: A Review of the MultiDisciplinary Literature. Journal of International Business Studies, 51(4), 577-622. https://doi.org/10.1057/s41267-020-00304-2

Karlina, B. (2017). Pengaruh Tingkat Inflasi, Indeks Harga Konsumen Terhadap PDB di Indonesia Pada Tahun 2011-2015. Jurnal Ekonomika Dan Manajemen, 6(1), 2252-6226. Retrieved from http://fe.budiluhur.ac.id/wpcontent/uploads/2017/08/b.-berlian.pdf

Kusdiyanti, H., Febrianto, I., \& Wijaya, R. (2020). Implementasi Smart Village Product Industrial Activity dalam Pengembangan Petani Jeruk Poncokusumo dalam Mewujudkan Sustainable Development' s Society. JURNAL ABIWARA, l(2), 54-59.

Larasati, I. S., \& Sulasmiyati, S. (2018). Pengaruh Inflasi, Ekspor, Dan Tenaga Kerja Terhadap Produk Domestik Bruto. Administrasi Bisnis, 63(1), 8-16. 
Lutfiana, I. M. (2017). Kontribusi Inflasi, Suku Bunga, Kurs, Produk Domestik Bruto Terhadap Harga Saham Kelompok Jakarta Islamic Index Di Indonesia Periode 2007-2015. An-Nisbah: Jurnal Ekonomi Syariah, 4(1). https://doi.org/10.21274/an.2017.4.1.75-104

Mcdonald, G. (2019). GAIN Report - Indonesia Coffee Annual Report 2019.

OECD/ERIA. (2018). SME Policy Index: ASEAN 2018: Boosting Competitiveness and Inclusive Growth. https://doi.org/10.1787/9789264305328-en

Ogundipe, A. A., Adu, O., Ogundipe, O. M., \& Asaleye, A. J. (2019). Macroeconomic Impact of Agricultural Commodity Price Volatility in Nigeria. The Open Agriculture Journal, 13(1), $162-174$

https://doi.org/10.2174/1874331501913010162

Patrick, G. (2017). Clustering and Product Innovativeness: A Literature Review of Small and Medium-Sized Enterprises (SMEs) in Kenya. International Journal of Academic Research in Economics and Management Sciences, $6(4)$. https://doi.org/10.6007/ijarems/v6-i4/3499

Prasanna, R. P. I. R., Jayasundara, J. M. S. B., Gamage, S. K. N., Ekanayake, E. M. S., Rajapakshe, P. S. K., \& Abeyrathne, G. A. K. N. J. (2019). Sustainability of SMEs in the competition: A systemic review on technological challenges and SME performance. Journal of Open Innovation: Technology, Market, and Complexity, 5(4), 118. https://doi.org/10.3390/joitmc5040100

Roostika, R. (2019). SMEs Craft Industry Application of Resource Based-View: Capabilities Role of SMEs Performance. Review of Integrative Business and Economics Research, 8(4), 423440.

Rosiana, N., Nurmalina, R., Winandi, R. ;, \& Rifin, A. (2017). The Level of Comparative Advantages of World Main Coffee Producers. Buletin Ilmiah Litbang Perdagangan, 11(2), 227-246.

Rusdiana, S., \& Maesya, A. (2018). Jurnal Sosial Ekonomi dan Kebijakan Pertanian. Jurnal Sosial Ekonomi Dan Kebijakan Pertanian, 7(2), 176-187. https://doi.org/http://dx.doi.org/10.21107/agriek onomika.v6il.1895
Şen, H., Kaya, A., Kaptan, S., \& Cömert, M. (2020). Interest rates, inflation, and exchange rates in fragile EMEs: A fresh look at the long-run interrelationships. Journal of International Trade and Economic Development, 29(3), 289318. https://doi.org/10.1080/09638199.2019.1663441

Silaban, P. S. M. J., \& Rejeki, R. (2020). Pengaruh Inflasi, Ekspor Dan Impor Terhadap Pdb Di Indonesia Periode 2015 - 2018. Niagawan, 9(1),56. https://doi.org/10.24114/niaga.v9i1.17656

Thanh, L. H., Nhat, L. T., Dang, H. N., Ho, T. M. H., \& Lebailly, P. (2018). One Village One Product (OVOP)-A rural Development Strategy and the Early Adaption in Vietnam, the Case of Quang Ninh Province. Sustainability (Switzerland), 10(12). https://doi.org/10.3390/su10124485

Thu, N. A. (2018). Exploring Consumers' Green Purchase Intention for a Packaged Food Product with Regard to Eco-Friendly Packaging: The Case of Packaged Instant Noodles in Vietnam. College of Business RMIT University Melbourne.

TPSA. (2017). Analisis Rantai Nilai Global untuk Ekspor Kopi Indonesia. Jakarta. 
16 Coopetition, Vol XII, Nomor 1, Maret 2021, 9 - 16

(E-ISSN : 2615-4978, P-ISSN : 2086-4620) 